\title{
Analisis Video Likes To Video Views Ratio Tiktok Pada 5 Team E-Sport Terkaya Di Dunia
}

\author{
I Gede Dian Manika Putra \\ STIMIK STIKOM Indonesia \\ okacita11@gmail.com
}

\begin{abstract}
TikTok is a social media application launched by a Chinese company. TikTok allows users to create 15 -second videos accompanied by music, filters, and several other creative features. Based on Tiktok's statistical data as of September 27, 2021, there are more than 1 billion active users and nearly 700 million monthly active global users, making Tiktok the most downloaded app in the world. The large number of active TikTok users in the world can certainly provide an opportunity for e-sports teams to make the TikTok platform a social media entertainment platform. There are 5 E-sports teams in the world that use TikTok as an entertainment platform, namely: Team SoloMid, Cloud9, Team Liquid, FaZe Clan, and 100 Thieves. The purpose of this study is to calculate the credibility of the TikTok account performance of the 5 Richest E-Sport Teams in the World. The method used in this research is an exploratory quantitative method. The results of this study indicate that Team Liquid is ranked first and has good account performance credibility.
\end{abstract}

\begin{abstract}
ABSTRAK
TikTok adalah aplikasi media sosial yang diluncurkan oleh perusahaan China. TikTok memungkinkan penggunanya membuat video berdurasi 15 detik disertai musik, filter, dan beberapa fitur kreatif lainnya. Berdasarkan data statistik Tiktok per 27 September 2021, terdapat lebih dari 1 miliar pengguna aktif dan hampir 700 juta pengguna global aktif bulanan, menjadikan Tiktok sebagai aplikasi yang paling banyak diunduh di dunia. Banyaknya pengguna aktif TikTok di dunia tentunya dapat memberikan peluang bagi tim e-sports untuk menjadikan platform TikTok sebagai platform hiburan media sosial. Adapun 5 Team E-sports Terkaya di Dunia yang menggunakan TikTok sebagai platform hiburan, diantaranya yaitu: Team SoloMid, Cloud9, Team Liquid, FaZe Clan, dan 100 Thieves. Tujuan dari penelitian ini adalah untuk menghitung kredibilitas kinerja akun TikTok dari 5 Tim E-Sport Terkaya di Dunia. Metode yang digunakan dalam penelitian ini adalah metode kuantitatif eksploratif. Hasil penelitian ini menunjukkan bahwa Team Liquid menduduki peringkat pertama dan memiliki kredibilitas kinerja akun yang baik.
\end{abstract}

Keyword : Credibility Account TikTok ; Social Media Entertainment ; Social Media TikTok ;Video Likes to Video Views Ratio ; Team E-sport Terkaya. 


\section{PENDAHULUAN}

Teknologi informasi dan komunikasi yang telah berkembang dengan pesat mampu menghantarkan manusia untuk menciptakan bentuk baru dalam cara berkomunikasi serta berinteraksi melalui media sosial. Media sosial memberikan pengaruh yang cukup besar, saat ini media sosial diajadikan sarana berkomunikasi dalam setiap aktifitas keseharian bersosial di masyarakat. Komunikasi tidak hanya dapat dilakukan secara fisik, tetapi juga dapat dilakukan dengan menggunakan berbagai aplikasi media sosial di dunia maya. Keunggulan layanan aplikasi sosial media adalah memberikan ruang komunikasi dua arah antara konsumenperusahaan dan konsumen-konsumen.

Dengan pesatnya perkembangan teknologi media sosial, telah memberikan dampak terhadap situs-situs komunikasi, dari yang awalnya hanya sekedar email dan chatting, saat ini sudah banyak jejaring media sosial yang bisa digunakan sebagai alat komunikasi. Contoh aplikasi sosial media yang memiliki banyak pengguna saat ini yaitu TikTok. TikTok merupakan aplikasi yang diluncurkan oleh perusahaan asal Tiongkok. Tiktok memungkinkan penggunanya membuat video berdurasi 15 detik yang disertai dengan musik, filter, dan beberapa fitur kreatif lainnya (Adawiyah 2020) .

Kehadiran media sosial TikTok dapat membangun sebuah brand, TikTok juga dapat membangun personal branding pemiliknya (Ishihara and Oktavianti 2021). Berdasarkan data statistik Tiktok per 27 September 2021, terdapat lebih dari 1 miliar pengguna aktif dan hampir 700 juta pengguna global aktif bulanan, menjadikan Tiktok sebagai aplikasi yang paling banyak diunduh di dunia. Banyaknya pengguna aktif TikTok di dunia tentunya dapat memberikan peluang bagi tim e-sports untuk menjadikan platform TikTok sebagai platform hiburan media sosial. Adapun 5 Team E-sports Terkaya di Dunia yang menggunakan TikTok sebagai platform hiburan, diantaranya yaitu: Team SoloMid, Cloud9, Team Liquid, FaZe Clan, dan 100 Thieves ("5 Tim E-Sport Terkaya di Dunia - merdeka.com").

Penelitian ini menggunakan metode eksploratif kuantitatif, dan akan menghitung menggunakan rasio-rasio yang ada pada TikTok. Pada penelitian (Permana and Meinarni 2021) menjelaskan bahwa terdapat 17 rasio yang ada pada sosial media TikTok dan relevan digunakan sebagai media ukur kredibilitas akun yang ada. Penelitian ini hanya berfokus untuk menghitung kredibilitas Video Likes to Video Views Ratio pada 5 Team E-Sport Terkaya di Dunia. Adapun 5 Team E-sports Terkaya di Dunia yang menggunakan TikTok sebagai platform hiburan, diantaranya yaitu: Team SoloMid, Cloud9, Team Liquid, FaZe Clan, dan 100 Thieves ("5 Tim E-Sport Terkaya di Dunia - merdeka.com"). Tujuan dari penelitian ini adalah mengetahui kredibilitas performa dari akun TikTok Top 5 Team E-Sport Terkaya di Dunia menggunakan Video Likes to Video Views Ratio. 


\section{TINJAUAN PUSTAKA}

Perkembangan bidang teknologi saat ini terjadi begitu pesat. Melalui perkembangan yang terjadi dari waktu ke waktu menimbulkan maraknya aplikasi-aplikasi serta platform media sosial yang bermunculan. Aplikasi yang sangat diminati oleh masyarakat saat ini diantaranya adalah TikTok, Instagram, Twitter, WhatsApp dan yang lain sebagainya. Seiring berjalannya waktu, aplikasi sosial media tersebut dapat menjadi candu bagi kalangan masyarakat. Tidak hanya kalangan remaja yang menggunakan aplikasi sosial media, orang tua bahkan anak-anak juga aktif menggunakan aplikasi sosial media tersebut.

Dari sekian banyak aplikasi sosial media, TikTok menjadi aplikasi yang memiliki pengguna aktif terbanyak. Tiktok adalah aplikasi media seluler yang memiliki tujuan utama "untuk video seluler format pendek" (Tiktok, 2020). Tiktok menyediakan fitur agar penggunanya dapat mengedit dengan efek, filter, teks dan musik, memotong, membuat gerakan lambat atau cepat dengan cara yang sangat mudah dan siapa saja dapat memahaminya. Tiktok memungkinkan para penggunanya untuk mengunggah video yang berdurasi 15 hingga 60 detik. Hal ini menjadikan TikTok sebagai hiburan yang menarik. Tiktok juga menyoroti bahwa misi mereka adalah untuk menginspirasi kreativitas dan membawa kegembiraan (Tiktok, 2020). Salah satu ciri khas sosial media TikTok adalah halaman utamanya yang Bernama For Your Page atau FYP. Pengguna yang cukup sering ditayangkan dalam FYP dapat menjadi populer dan memiliki banyak pengikut, yang biasa disebut sebagai seleb TikTok (Putri and Azeharie 2021).

Konten memiliki peran penting dalam industri kreatif pada media sosial TikTok. Dikutip dari laman Statista yang ditulis oleh Clement (2020) terdapat beberapa kategori konten di aplikasi TikTok yaitu meliputi konten dance, pranks, hiburan, kebugaran/olahraga, DIY, kecantikan, fashion, recipes, lifehacks, pets, dan 3 outdoor. Kategori konten yang sangat populer dan paling banyak dilihat di aplikasi TikTok berdasarkan tampilan hastag pada Juni 2020 adalah konten hiburan. Konten hiburan telah dilihat sebesar 443,3 Miliar kemudian diikuti konten dance memasuki peringkat kedua dengan total sebesar 150,3 Miliar tampilan hashtag (Clement, 2020). Berdasarkan keterangan dari Media Indonesia (2019) TikTok berhasil menjadi aplikasi hiburan nomor satu di App Store di Indonesia dan pada tahun 2018 Tiktok mendapatkan penghargaan dari Google Play sebagai “Aplikasi Paling Menghibur" dan "Aplikasi Terbaik".

TikTok dirasakan memiliki kekuatan ataupun pengaruh dalam industri, sehingga menimbulkan kualitas akun yang menentukan strata maupun kredibilitas pemilik akun. Kredibilitas akun TikTok merupakan suatu hal yang cukup penting untuk berbagai kepentingan. Kredibilitas sebuah akun TikTok dapat diukur dari tingkat performa yang dihasilkan secara matematis. Dalam mengukur performa diperlukan skala pengukuran yang tertuang ke dalam rasio. 


\section{METODE PENELITIAN}

Penelitian ini menggunakan metode eksploratif kuantitatif untuk mengetahui kredibilitas dari performa akun TikTok 5 Team E-Sport Terkaya di Dunia. Metode eksploratif merupakan penelitian yang memiliki tujuan untuk melakukan eksplorasi atau memperdalam pengetahuan ataupun ide-ide baru mengenai suatu hal yang baru, guna merumuskan permasalahan secara terperinci (Maryam, Isrok'atun, and Aeni 2016). Tujuan dari penelitian ini yaitu untuk mengetahui nilai kredibillitas dari performa akun TikTok 5 Team E-Sport Terkaya di Dunia. Adapun beberapa langkah yang harus dilakukan dalam penelitian ini, sehingga mampu menemukan peringkat pertama akun TikTok Team E-Sport Terkaya di Dunia yang memiliki performa terbaik.

Langkah-langkah yang dilakukan pada penelitian ini, diantaranya yaitu :

\section{Melakukan Eksplorasi Pada Website Untuk Menentukan Objek yang Akan Dianalisa.}

Eksplorasi ini dilakukan pada beberapa halaman website yang menyediakan informasi mengenai objek yang akan di teliti. Setelah eksplorasi selesai dilakukan, sehingga ditemukan nama-nama Team E-Sport Terkaya di Dunia yang akan dijadikan objek analisa. Setelah melakukan eksplorasi pada halaman website, maka langkah selanjutnya yaitu mencari nama akun TikTok dari masing-masing tim e-sport.

\section{Menghitung Nilai Rata-Rata Variable Dari Top 5 Vendor Smartphone di Indonesia.}

Pada langkah ini, peneliti menghitung nilai variable video likes dan variable video views. Variabel merupakan sesuatu yang memiliki nilai bervariasi dimana nilai tersebut dapat dijadikan sebagai dasar untuk empat data yang berbeda seperti rasio, skala, ordinal, nominal dan internal (Rankuti 2015). Untuk menghitung nilai rata-rata dari variabel video likes dan variabel video views yaitu dengan cara mengambil minimal 10 postingan kemudian di hitung sehingga menemukan nilai rata-rata dari masing-masing variabel.

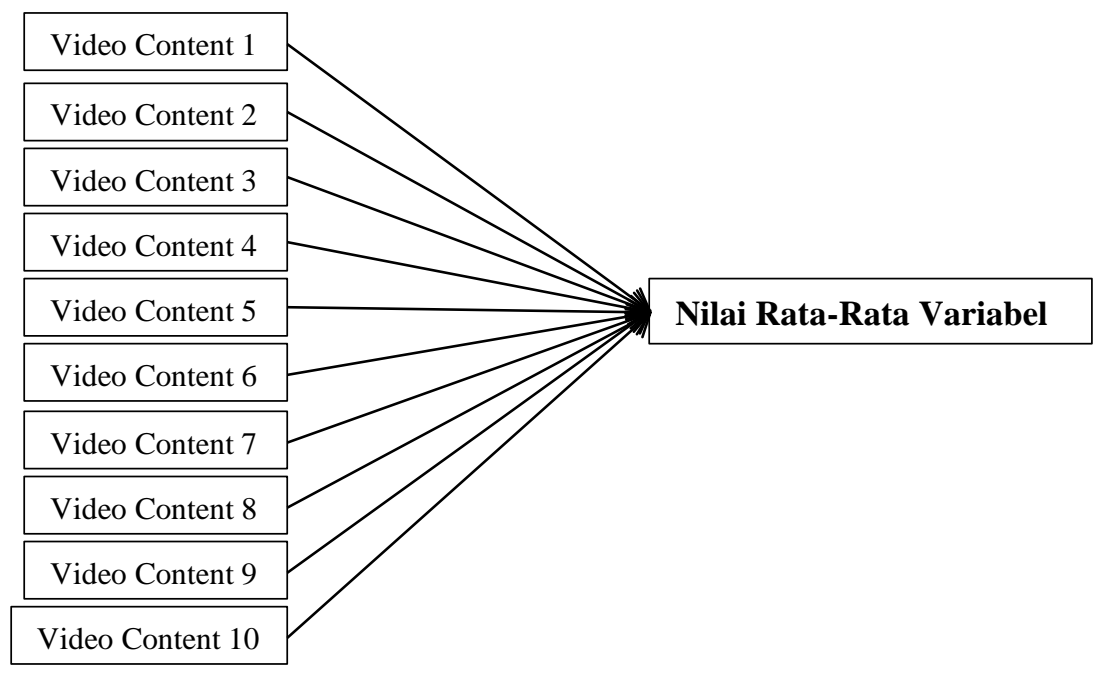




\section{Menghitung Nilai Kredibilitas Rasio}

Untuk menghitung nilai kredibilitas dari video comments to video views ratio, peneliti menggunakan cara membagi nilai variabel pertama dengan nilai variabel kedua. Jika video likes memiliki nilai 100 dan video views memiliki nilai 300, maka cara menghitungnya yaitu $100: 300=0,3$. Dengan begitu nilai dari video likes to video views ratio adalah 0,3 .

\section{Menentukan Peringkat Pada Akun TikTok}

Pada langkah terakhir yang dilakukan pada penelitian ini yaitu menentukan peringkat pada masing-masing rasio yang ada. Pada penentuan peringkat perlu melihat karakteristik dari rasio yang di teliti. Jika karakteristik rasio merupakan rendah, maka objek yang memiliki nilai terendah akan mendapatkan angka 5 dan objek yang memiliki nilai tertinggi akan mendapatkan angka 1. Namun jika rasio memiliki karakteritik tinggi maka objek yang mendapatkan nilai tinggi akan mendapatkan angka 5 dan objek yang mendapatkan nilai terendah akan mendapatkan angka 1. Setelah mendapatkan hasil kredibilitas ratio maka dapat disimpulkan objek yang mana mendapatkan peringkat 1 sampai dengan peringkat 5 .

\section{HASIL DAN PEMBAHASAN}

Akun Tiktok Top 5 Team E-Sport Terkaya di Dunia, diantaranya :

\section{Team SoloMid}

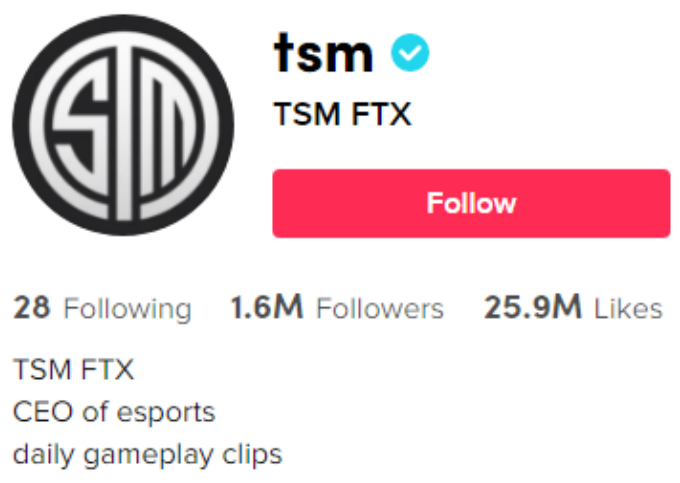

Gambar 1. Akun Tiktok Team SoloMid 


\section{Cloud9}

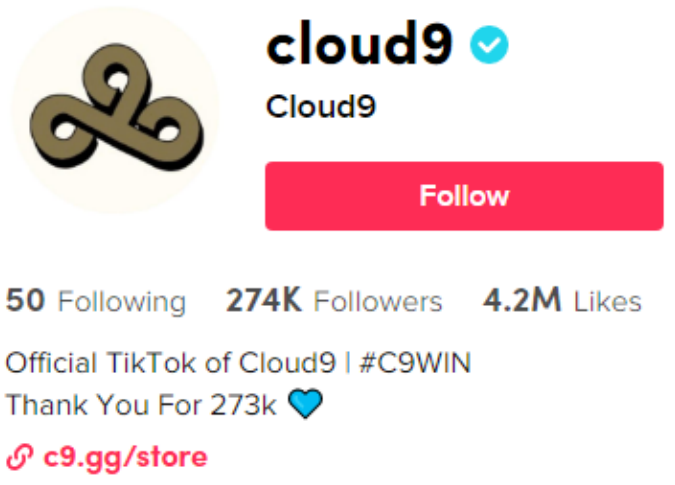

Gambar 2. Akun Tiktok Cloud9

Sumber : https://www.tiktok.com/@cloud9? (Akses pada 22-10-2021)

\section{Team Liquid}

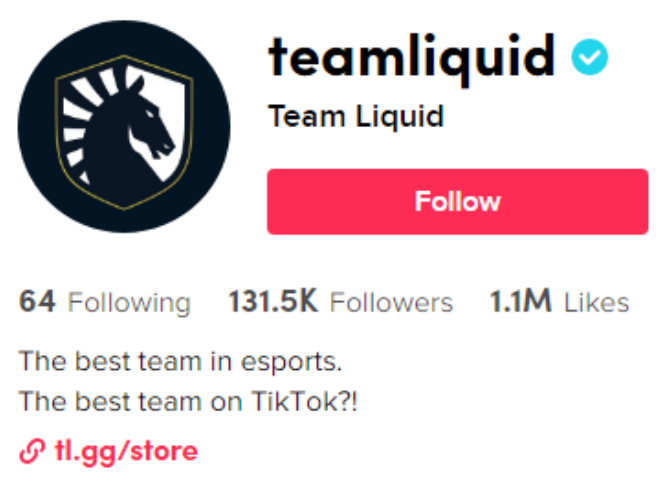

Gambar 3. Akun Tiktok Team Liquid

Sumber : https://www.tiktok.com/@teamliquid? (Akses pada 22-10-2021)

\section{FaZe Clan}

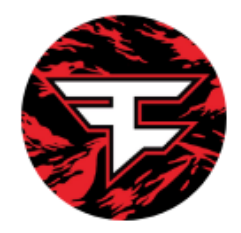

fazeclan

FaZe Clan

\section{Follow}

44 Following 6M Followers 96.7M Likes

The world's largest gaming team \#FaZeUp

$\odot$ youtu.be/oiY8yujLo5U 


\section{100 Thieves}

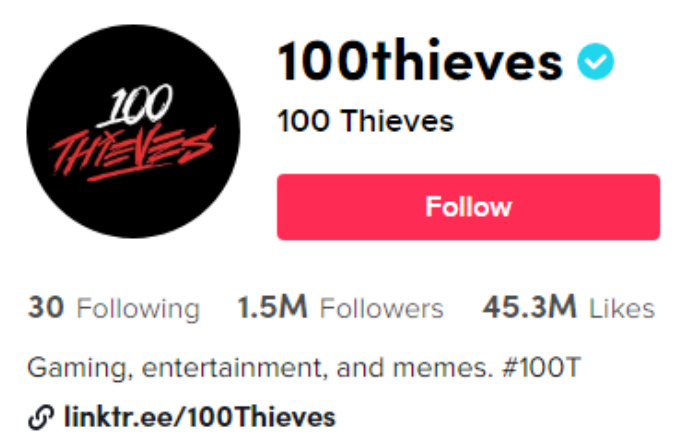

Gambar 5. Akun Tiktok 100 Thieves

Sumber : https://www.tiktok.com/@100thieves? (Akses pada 22-10-2021)

Dari kelima akun TikTok Top 5 Team E-Sport Terkaya di Dunia, peneliti menemukan nilai dari masing-masing variabel yang ada untuk menghitung rasio Video Likes to Video Views dari setiap akun. Pada akun TikTok terdapat 7 variabel, diantaranya yaitu :

1. Likes

2. Followers

3. Following

4. Video Likes

5. Video Comments

6. Video Share

7. Video Views

Dari ketujuh variabel tersebut peneliti hanya fokus untuk menemukan hasil dari 2 variabel pada akun tiktok, yaitu :

1. Video Likes

2. Video Views

Dari kedua variabel tersebut kemudian dianalisa sehingga menemukan nilai rata-rata dari variabel video likes dan variabel video views. Untuk menghitung nilai rata-rata dari variabel video likes dan variabel video views yaitu dengan cara mengambil minimal 10 postingan kemudian di hitung sehingga menemukan nilai rata-rata dari masing-masing variabel. Berikut merupakan tabel nilai rata-rata dari masing-masing Team E-Sport Terkaya di Dunia, yaitu : 
Tabel 1. Analisa Nilai Rata-Rata Nilai Variabel Video Likes dan Video Views Akun TikTok Team SoloMid

\begin{tabular}{|c|r|r|}
\hline No & Video Like & Video View \\
\hline $\mathbf{1}$ & 4.679 & 45.400 \\
\hline $\mathbf{2}$ & 4.978 & 34.100 \\
\hline $\mathbf{3}$ & 6.329 & 53.900 \\
\hline $\mathbf{4}$ & 16.800 & 111.300 \\
\hline $\mathbf{5}$ & 3.344 & 26.800 \\
\hline $\mathbf{6}$ & 2.085 & 16.400 \\
\hline $\mathbf{7}$ & 7.706 & 46.500 \\
\hline $\mathbf{8}$ & 3.750 & 22.800 \\
\hline $\mathbf{9}$ & 2.901 & 26.400 \\
\hline $\mathbf{1 0}$ & 3.855 & 30.200 \\
\hline Total & $\mathbf{5 . 6 4 2 7}$ & $\mathbf{4 1 . 3 8 0}$ \\
\hline
\end{tabular}

Sumber : Pengolah Data Excel

Tabel 2. Analisa Nilai Rata-Rata Nilai Variabel Video Likes dan Video Views Akun TikTok Cloud9

\begin{tabular}{|c|r|r|}
\hline No & Video Like & Video View \\
\hline $\mathbf{1}$ & 4.369 & 34.800 \\
\hline $\mathbf{2}$ & 8.969 & 66.400 \\
\hline $\mathbf{3}$ & 41.600 & 308.7 \\
\hline $\mathbf{4}$ & 57.500 & 388.2 \\
\hline $\mathbf{5}$ & 2.363 & 19.200 \\
\hline $\mathbf{6}$ & 186.5 & 1.400 .000 \\
\hline $\mathbf{7}$ & 3.660 & 47.100 \\
\hline $\mathbf{8}$ & 21.800 & 145.1 \\
\hline $\mathbf{9}$ & 8.769 & 68.700 \\
\hline $\mathbf{1 0}$ & 9.161 & 91.900 \\
\hline Total & $\mathbf{3 4 . 4 6 9 1}$ & $\mathbf{1 3 0 . 0 1 1 1 1 1 1}$ \\
\hline
\end{tabular}

Sumber : Pengolah Data Excel 
Tabel 3. Analisa Nilai Rata-Rata Nilai Variabel Video Likes dan Video Views Akun TikTok Team Liquid

\begin{tabular}{|c|r|r|}
\hline No & Video Like & Video View \\
\hline $\mathbf{1}$ & 139 & 1.245 \\
\hline $\mathbf{2}$ & 1.571 & 13.100 \\
\hline $\mathbf{3}$ & 1.034 & 9.810 \\
\hline $\mathbf{4}$ & 193 & 1.904 \\
\hline $\mathbf{5}$ & 409 & 3.302 \\
\hline $\mathbf{6}$ & 116 & 1.369 \\
\hline $\mathbf{7}$ & 119 & 2.241 \\
\hline $\mathbf{8}$ & 38.500 & 325.9 \\
\hline $\mathbf{9}$ & 2.295 & 21.500 \\
\hline $\mathbf{1 0}$ & 282 & 4.192 \\
\hline Total & $\mathbf{1 3 0 . 1 4}$ & $\mathbf{3 8 4 . 5 6 3}$ \\
\hline
\end{tabular}

Sumber : Pengolah Data Excel

Tabel 4. Analisa Nilai Rata-Rata Nilai Variabel Video Likes dan Video Views Akun TikTok FaZe Clan

\begin{tabular}{|c|r|r|}
\hline No & Video Like & Video View \\
\hline $\mathbf{1}$ & 1.000 .000 & 7.600 .000 \\
\hline $\mathbf{2}$ & 6.733 & 84.001 \\
\hline $\mathbf{3}$ & 6.651 & 67.700 \\
\hline $\mathbf{4}$ & 35.900 & 229.700 \\
\hline $\mathbf{5}$ & 15.800 & 162.900 \\
\hline $\mathbf{6}$ & 130.800 & 856.400 \\
\hline $\mathbf{7}$ & 72.200 & 546.600 \\
\hline $\mathbf{8}$ & 251.7 & 1.600 .000 \\
\hline $\mathbf{9}$ & 72.800 & 685.500 \\
\hline $\mathbf{1 0}$ & 52.600 & 461.400 \\
\hline Total & $\mathbf{7 1 . 6 8 7 1 1 1 1 1}$ & $\mathbf{3 8 6 . 7 7 5 1 2 5}$ \\
\hline
\end{tabular}

Sumber : Pengolah Data Excel 
Tabel 5. Analisa Nilai Rata-Rata Nilai Variabel Video Likes dan Video Views Akun TikTok 100 Thieves

\begin{tabular}{|c|r|r|}
\hline No & Video Like & Video View \\
\hline $\mathbf{1}$ & 11.900 & 74.900 \\
\hline $\mathbf{2}$ & 1.325 & 9.201 \\
\hline $\mathbf{3}$ & 14.700 & 70.700 \\
\hline $\mathbf{4}$ & 15.200 & 70.400 \\
\hline $\mathbf{5}$ & 11.400 & 56.030 \\
\hline $\mathbf{6}$ & 11.004 & 65.004 \\
\hline $\mathbf{7}$ & 9.239 & 59.700 \\
\hline $\mathbf{8}$ & 7.491 & 50.700 \\
\hline $\mathbf{9}$ & 63.100 & 496.300 \\
\hline $\mathbf{1 0}$ & 27.100 & 149.900 \\
\hline Total & $\mathbf{1 7 . 2 4 5 9}$ & $\mathbf{1 1 0 . 2 8 3 5}$ \\
\hline
\end{tabular}

Sumber : Pengolah Data Excel

Setelah menghitung nilai rata-rata tersebut, maka akan menemukan hasil akhir nilai rata-rata dari variabel video likes dan video views.

Tabel 6. Nilai Variabel Pada Akun TikTok Top 5 Team E-Sport Terkaya di Dunia

\begin{tabular}{|l|r|r|r|r|r|}
\hline \multicolumn{1}{|c|}{ Variable } & Team SoloMid $\nabla$ & \multicolumn{1}{c}{ Cloud9 } & Team Liquid $\nabla$ & FaZe Clan & $\nabla$ \\
\hline Video Likes & 5.6427 & 34.4691 & 130.14 & 71.68711111 & 17.2495 \\
\hline Video Views & 41.38 & 133.111111 & 384.563 & 386.775125 & 110.2835 \\
\hline
\end{tabular}

Sumber : Pengolah Data Excel

Pada akun TikTok terdapat 17 rasio yang relevan digunakan untuk mengukur kredibilitas pada masing-masing akun. Namun pada penelitian kali ini hanya berfokus untuk menghitung Video Likes to Video Views Ratio. Untuk menghitung kredibilitas dari masing-masing akun TikTok setiap team e-sport, peneliti menghitung dengan cara : variabel 1 akan dibagi dengan variabel 2, sehingga ditemukan hasil analisisa dari rasio tersebut.

Tabel 7. Hasil Perhitungan Rasio Akun TikTok

\begin{tabular}{|c|c|c|c|c|c|c|c|}
\hline No 7 & RATIO & Team SoloMid $\mathrm{v}$ & Cloudg & Team Liquid $\nabla$ & Faze Clan $\nabla$ & 100 Thieves $\nabla$ & Karakteristik \\
\hline 1 & Video Likes to Video Views & 0.13636297728 & 0.25894983327 & 0.33841009145 & 0.18534571247 & 0.15641052378 & Tinggi \\
\hline
\end{tabular}

Sumber : Pengolah Data Excel 
Video Likes to Video Views Ratio memiliki karakteristik yang tinggi, artinya semakin tinggi nilai yang dihasilkan maka semakin baik kredibilitas dari performa akun tersebut. Untuk memberikan peringkat pada masing-masing Team E-Sport, peneliti memberikan angka 5 kepada team yang mendapatkan nilai tertinggi dan angka 1 untuk team e-sport yang mendapatkan nilai terendah. Berikut merupakan tabel urutan nilai yang dihasilkan oleh masing-masing team esport.

Tabel 8. Nilai Rasio Akun TikTok Top 5 Team E-Sport Terkaya di Dunia

\begin{tabular}{|c|c|c|c|}
\hline No & Nama Team & Column1 & Ranking \\
\hline 1 & Team SoloMid & 0.13636297728 & 1 \\
\hline 2 & Cloud9 & 0.25894983327 & 4 \\
\hline 3 & Team Liquid & 0.33841009145 & 5 \\
\hline 4 & FaZe Clan & 0.18534571247 & 3 \\
\hline 5 & 100 Thieves & 0.15641052378 & 2 \\
\hline
\end{tabular}

Sumber : Pengolah Data Excel

Dari Tabel Nilai Rasio Akun TikTok Top 5 Team E-Sport Terkaya di Dunia dapat simpulkan bahwa Team Liquid mendapatkan nilai tertinggi untuk rasio Video Likes to Video Views. Sedangkan akun TikTok Team SoloMid mendapatkan nilai terendah untuk rasio ini. Jadi, pada penelitian ini Team Liquid memiliki kredibilitas performa yang lebih baik dibandingkan dengan team e-sport yang lainnya.

\section{KESIMPULAN}

Tujuan dari penelitian ini adalah mengetahui kredibilitas performa dari akun TikTok Top 5 Team E-Sport Terkaya di Dunia menggunakan Video Likes to Video Views Ratio. Top 5 Team ESport Terkaya di Dunia tersebut diantaranya : Team SoloMid, Cloud9, Team Liquid, FaZe Clan, dan 100 Thieves. Dari kelima team e-sport tersebut dapat disimpulkan bahwa :

1. Peringkat pertama diraih oleh Team Liquid Indonesia dengan nilai tertinggi yaitu 0.33841009145

2. Peringkat kedua diraih oleh Cloud9 dengan nilai 0.25894983327

3. Peringkat ketiga diraih oleh FaZe Clan dengan nilai 0.18534571247

4. Peringkat keempat diraih oleh 100 Thieves dengan nilai 0.15641052378

5. Peringkat kelima diraih oleh Team SoloMid dengan nilai terendah yaitu 0.13636297728 


\section{DAFTAR PUSTAKA}

Ishihara, Yemikaori Yumna Ulya, and Roswita Oktavianti. "Personal Branding Influencer Di Media Sosial TikTok.” Koneksi, vol. 5, no. 1, 2021, pp. 76-82, https://doi.org/10.24912/kn.v5i1.10162.

Adawiyah, Dwi Putri Robiatul. "Pengaruh Penggunaan Aplikasi TikTok Terhadap Kepercayaan Diri Remaja Di Kabupaten Sampang.” Jurnal Komunikasi, vol. 14, no. 2, 2020, pp. 135-48, https://doi.org/10.21107/ilkom.v14i2.7504.

Putri, Shani Dwi, and Suzy Azeharie. Strategi Pengelolaan Komunikasi Dalam Membentuk Personal Branding Di Media Sosial Tiktok. no. 2, 2021, pp. 280-88, https://doi.org/10.24912/kn.v5i2.10300.

Maryam, Siti, and Ani Nur Aeni. "Pendekatan Eksploratif Untuk Meningkatkan Kemampuan Representasi Matematis Dan Kepercayaan Diri Siswa.” Jurnal Pena Ilmiah, vol. 1, no. 1, 2016, pp. 551-60, https://doi.org/10.23819/pi.v1i1.2984.

Permana, I., \& Meinarni, N. Ratio Analysis on Tiktok (Social Media) for Qualitative Research Using Explorative Methods. Jurnal Ekonomi \& Bisnis JAGADITHA, vol. 8, no. 1, 2021, pp. 30-38. https://doi.org/10.22225/jj.8.1.2944.30-38

Celement. "TikTok- Statistics \& Facts." Statista.Com, 2020, p. TikTok-Statistics \& Facts, https://www.statista.com/topics/6077/tiktok/\#dossierKeyfigures.

Cahya, Indra. "5 Tim Esports Terkaya Di Dunia Tahun 2020.” Merdeka.Com, 2020, p. Teknologi, https://www.merdeka.com/teknologi/5-tim-esports-terkaya-di-dunia-tahun2020.html.

Tiktok. “Tiktok. Our Mission.” Www.Tiktok.Com, 2020, p. Our Mission, https://www.tiktok.com/about?lang=en.

TikTok. Tiktok.com, 2016, p. Make Your Day, https://www.tiktok.com/. 